\section{PEER-REVIEWED ARTICLE}

Food Protection Trends, Vol 41, No. 4, p. 400-408 Copyright ${ }^{\circledR}$ 2021, International Association for Food Protection 2900 100th Street, Suite 309, Des Moines, IA 50322-3855, USA
Lillian Nabwiire, ${ }^{1,2}$ Angela M. Shaw, ${ }^{1 *}$ Gail R. Nonnecke, ${ }^{2}$ David Minner, ${ }^{2}$ Ellen Johnsen ${ }^{1}$ and Louis Petersen ${ }^{3}$

${ }^{1}$ Dept. of Food Science and Human Nutrition, lowa State University, 2312 Food Sciences Bldg., 536 Farm House Lane, Ames, IA 50011-1057, USA 2Dept. of Horticulture, lowa State University, 106 Horticulture Hall, Ames, IA 50011, USA ${ }^{3}$ Cooperative Extension Service, University of the Virgin Islands, St. Thomas, U.S. Virgin Islands

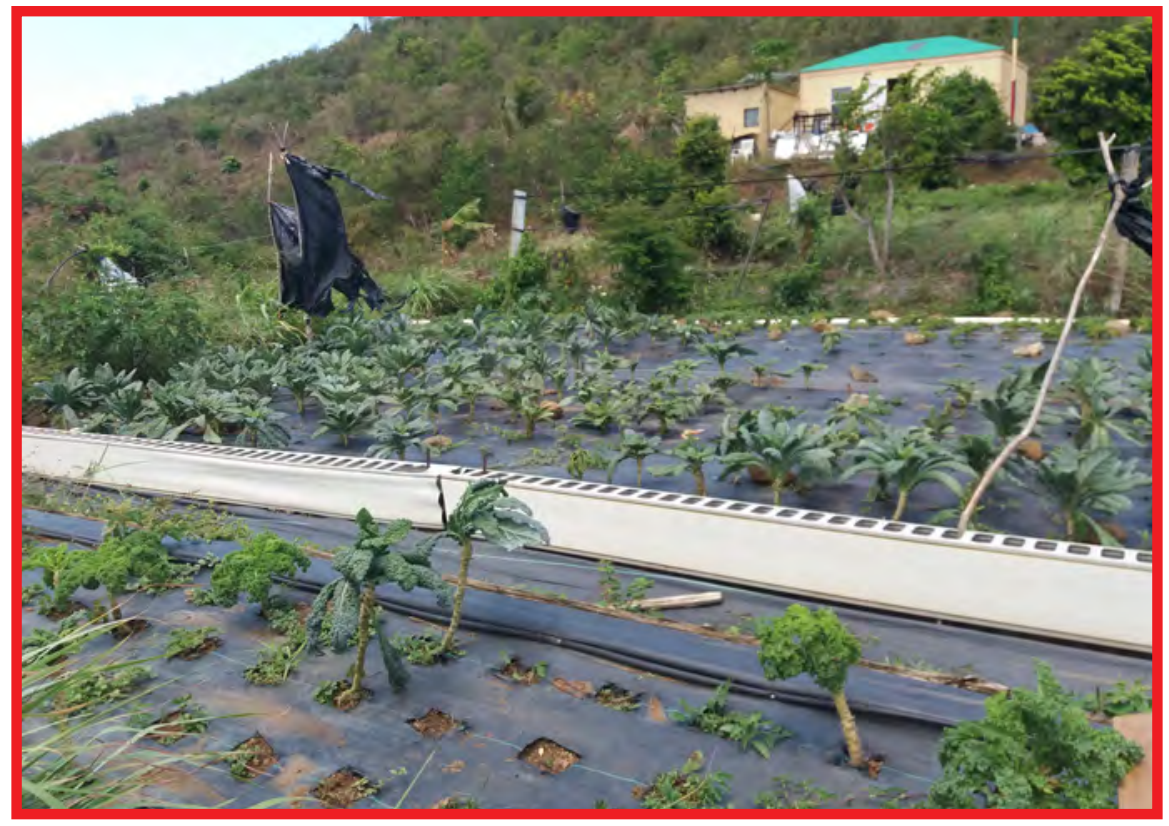

\title{
Addressing Food Safety Educational Needs of Food Handlers in the U.S. Virgin Islands
}

\section{ABSTRACT}

Between 2009 and 2015, restaurants represented $61 \%$ of foodborne illnesses in the United States. Cultural differences among food handlers have been shown to pose challenges in compliance with food safety practices in restaurants. The hypothesis was that culturally appropriate, needs-based food safety education intervention for the food service industry in the U.S. Virgin Islands would increase positive food safety behaviors. Face-to-face interviews based on the U.S. Food and Drug Administration 2013 Food Code were conducted with 28 restaurant managers and seven key informants to identify food safety knowledge and behavior gaps. Food safety training flip charts, posters, and signs addressing gaps were developed and pilot tested before dissemination. Behavioral change was assessed 6 months after dissemination. Food safety knowledge and behavioral gaps included inadequate hygiene and sanitation, time and temperature abuse of food, cross-contamination, and lowquality food. Respondents requested that their customs, food, and people be represented within training materials.
Developed materials were used to train 89 employees (from 11 restaurants), and personal hygiene practices ( $n$ = 12 incidents), temperature control ( $n=7)$, preventing cross-contamination ( $n=8$ ), and cleaning food contact surfaces ( $n=7$ ) had changed after 6 months. On site, culturally appropriate food safety education interventions were found to be effective at promoting food safety practices in culturally diverse populations.

\section{INTRODUCTION}

Tourism is the predominant component of the U.S. Virgin Islands (USVI) economy (11). In 2018, the total number of tourist arrivals in the USVI was reduced by 734,780 compared with the previous year because of infrastructure destruction caused by 2017 hurricanes (7). In 2019, with the USVI infrastructure recovered, tourist arrivals increased by 501,862 and stayover tourists increased by $50 \%$ (39). During the high tourism months of November through March, restaurants in USVI serve more customers, yet the number of employees may not increase as necessary to ensure food safety practices. Risk factors contributing to foodborne 
illnesses and outbreaks in retail food establishments in the United States include contaminated equipment, food from unsafe sources, time and temperature abuse when cooking and holding, and inadequate personal hygiene and health (3, 4, 16, 41). Between 2009 and 2019, 76 inspections were conducted in the food or cosmetics enterprises in the USVI, and during 40 of these inspections, citations were issued following noncompliance that would lead to biological hazards in food (43).

In April 2012, a norovirus outbreak linked to no specific food from the hotel kitchen made 20 employees and 46 guests sick in a hotel resort on St. Thomas Island, USVI. The implicated pathogen spread from hotel employees to the guests within 5 days (23). A study to evaluate the food safety knowledge of foodservice workers at a university campus in the Republic of Trinidad and Tobago found that respondents had inadequate knowledge about time and temperature control of food and about cleaning and sanitizing food contact surfaces, and they could not identify a sick food handler (49).

The U.S. Food and Drug Administration (FDA) Food Code (41) provides recommendations for the safe handling of food in retail and food service establishments to protect the public from foodborne illnesses. Compliance with these recommendations is monitored and enforced through routine inspections at least once in every 6 months by state and local government agencies (41). Food-handler training such as the ServSafe provide food safety knowledge, but the knowledge may not translate to behavioral change $(12,50)$. This disconnect could be associated with barriers such as lack of resources needed to perform food-safety practices, negligence by management, time constraints, lack of motivation, or training that is usually undertaken away from the facilities where knowledge is supposed to be applied $(2,15,18,33)$. The USVI population is diverse in race and socioeconomic status and speaks several languages, including English, Spanish, and Creole, and its diversity is seen within the food handler population $(38,47)$. Food safety extension educators have a challenge to effectively communicate with culturally diverse populations that speak different languages (30).

To meet unique food safety education needs and bring about positive change in behavior and practices, USVI food handlers may benefit from onsite and culturally appropriate food safety resources $(5,34)$. The purpose of this study was to identify the key food safety concerns within the USVI's food service industry and develop onsite, culturally appropriate training resources on topics of food safety to address these concerns. The hypothesis was that culturally appropriate and needs-based intervention in food safety education for the food service industry would increase positive behaviors in food safety practices.

\section{MATERIALS AND METHODS}

The study was conducted in the USVI, including St. John, St. Thomas, and St. Croix, from summer 2018 to spring 2020, following approval by Iowa State University's Institutional Review Board (IRB ID 18-209). The study was completed in three phases, starting with a needs assessment, followed by development and validation of food safety educational materials, and finishing with assessment of the impact of developed materials on food-handling practices.

\section{Phase 1: Needs assessment}

In the summer of 2018, 35 face-to-face focused interviews were conducted with seven key informants, 23 restaurant managers and chefs, three roadside food vendors, and two cooks in charity kitchens. A 5- to 10-min observation of activities at all food establishments was conducted after the face-to-face surveys completed by oral interviews. Survey questions and observations were based on the FDA's 2013 Food Code (41), a version that would have been followed in 2018. The survey covered key topics, including temperature control, food preparation, serving and holding practices, food source, hygiene and sanitation, cross-contamination, and food defense. The survey tool used was modified from a validated tool by Sneed et al. (37) to include only questions relevant to the hypothesis. Qualitative data including establishment characteristics and prevailing food-handling practices were written in a notebook and/ or recorded with an audio recorder (the method used was based on agreement with the interviewee). Transcription followed by qualitative coding occurred using the FDA 2013 Food Code requirements. Based on the coding, knowledge and behavioral gaps and potential food safety risks were identified. The four most frequent coding themes were used for the phase 2 educational materials.

\section{Phase 2: Development and evaluation of food safety educational materials}

Based on the phase 1 results, training flip charts, posters, and signs were developed to train food handlers. Materials were designed to include figures, photographs, and minimal text. This study used a behavior-based intervention, because previous studies found that such interventions are effective at improving food handling practices $(36,51)$. Materials were evaluated twice, with the first evaluation completed by 11 participants, including 10 restaurant managers and a food inspector from the USVI Department of Health, and the second round completed by 24 restaurant managers. In both evaluations, the design and content of materials were evaluated based on the validated tool with nine criteria using a Likert scale of 1 to 5 ( $1=$ criteria not met and $5=$ criteria totally met $)$ (31). The decision about the use of materials depended on the total scores obtained (Table 1) (31). Six cultural sensitivity questions and a comments section were included in the survey. The average of total scores was calculated using Microsoft Excel (Table 2). The difference between the averages of total scores for the two evaluations was tested using a t-test at a 0.05 significance level and JMP software (version 15; Cary, NC). The percentage of respondents who answered yes or no to cultural sensitivity questions was calculated. 
TABLE 1. Range of scores and their related decision about revision of materials before use (31)

\begin{tabular}{c|c} 
Score & Decision \\
\hline $40-45$ points & No need for revision before use \\
\hline $21-39$ points & Revise before use \\
\hline $0-20$ points & Reject, do not use \\
\hline
\end{tabular}

TABLE 2. Average evaluation score of specific criteria, for initial (evaluation 1) and revised (evaluation 2) materials shared with retail food establishment managers in the USVI

\begin{tabular}{l|c|c} 
Question about specific criteria & $\begin{array}{c}\text { Evaluation 1 average } \pm \\
\text { standard deviation } \\
(\boldsymbol{n}=\mathbf{1 1})\end{array}$ & $\begin{array}{c}\text { Evaluation 2 average } \pm \\
\text { standard deviation } \\
(\boldsymbol{n}=\mathbf{2 4})\end{array}$ \\
\hline Do the materials fully present specific themes? & $4.82 \pm 0.41$ & $4.88 \pm 0.34$ \\
\hline Is the content or message easily understood? & $4.91 \pm 0.30$ & $4.92 \pm 0.28$ \\
\hline Do the illustrations clarify or complement the written parts? & $4.91 \pm 0.30$ & $4.88 \pm 0.34$ \\
\hline Is the size of the letters easy to read? & $4.45 \pm 0.32$ & $4.96 \pm 0.20$ \\
\hline Do the materials provide a synopsis of the message or content? & $4.91 \pm 0.30$ & $4.92 \pm 0.28$ \\
\hline $\begin{array}{l}\text { Do the materials have aspects that emphasize important ideas, such as type, size, } \\
\text { style, or color of certain parts? }\end{array}$ & $4.82 \pm 0.41$ & $4.96 \pm 0.20$ \\
\hline Are the writing style, grammar, and punctuation appropriate for the audience? & $4.82 \pm 0.41$ & $4.92 \pm 0.28$ \\
\hline Do the materials avoid information overload or too much writing in one place? & $4.55 \pm 0.93$ & $4.75 \pm 0.68$ \\
\hline Do the materials use language easily understood by the target audience? & $4.82 \pm 0.41$ & $4.96 \pm 0.20$ \\
\hline Total & $43 \pm 3.13 \mathrm{~A}^{a}$ & $44.1 \pm 2.21 \mathrm{~A}$ \\
\hline
\end{tabular}

${ }^{a}$ Average total scores with same letter are not significantly different $(P>0.05)$.

After the first evaluation, materials were modified as requested by respondents, including increasing the size of posters, adding more photographs representing USVI

(Fig. 1), creating more food safety signs, and translating signs into the Spanish language (Fig. 2). Modified materials were reviewed and approved by Iowa State University Extension and Outreach and printed for dissemination. The size of signs was 11 in. by 8.5 in., the flip chart was 14 in. by 11 in., and the posters were 27 in. by 18 in. Participating restaurant owners and managers were given materials and shown how to use them to educate their employees.

Phase 3: Evaluating the impact of food safety education intervention on food-handling practices

The impact of food safety educational materials on food handling practices was assessed 6 months after dissemination by conducting a self-administered electronic survey (version
XM; Qualtrics, Provo, UT; $n=6)$ or a paper-printed survey $(n=5)$, both with the same questions. The survey was completed by 11 restaurant managers and chefs, who reported how the extension materials were used, changes in practices and behavior at their establishments, factors contributing to the changes, and challenges experienced while using the educational materials. The frequency of responses under each of these sections was calculated.

\section{RESULTS AND DISCUSSION}

\section{Characteristics of the USVI food service industry}

The food inspectors within the USVI Department of Health require an operation permit for each food service establishment, conduct inspections of establishments, and require all food handlers to have a health card before they start to work (45). Based on our interviews conducted with personnel from the USVI Department of Health, the health 

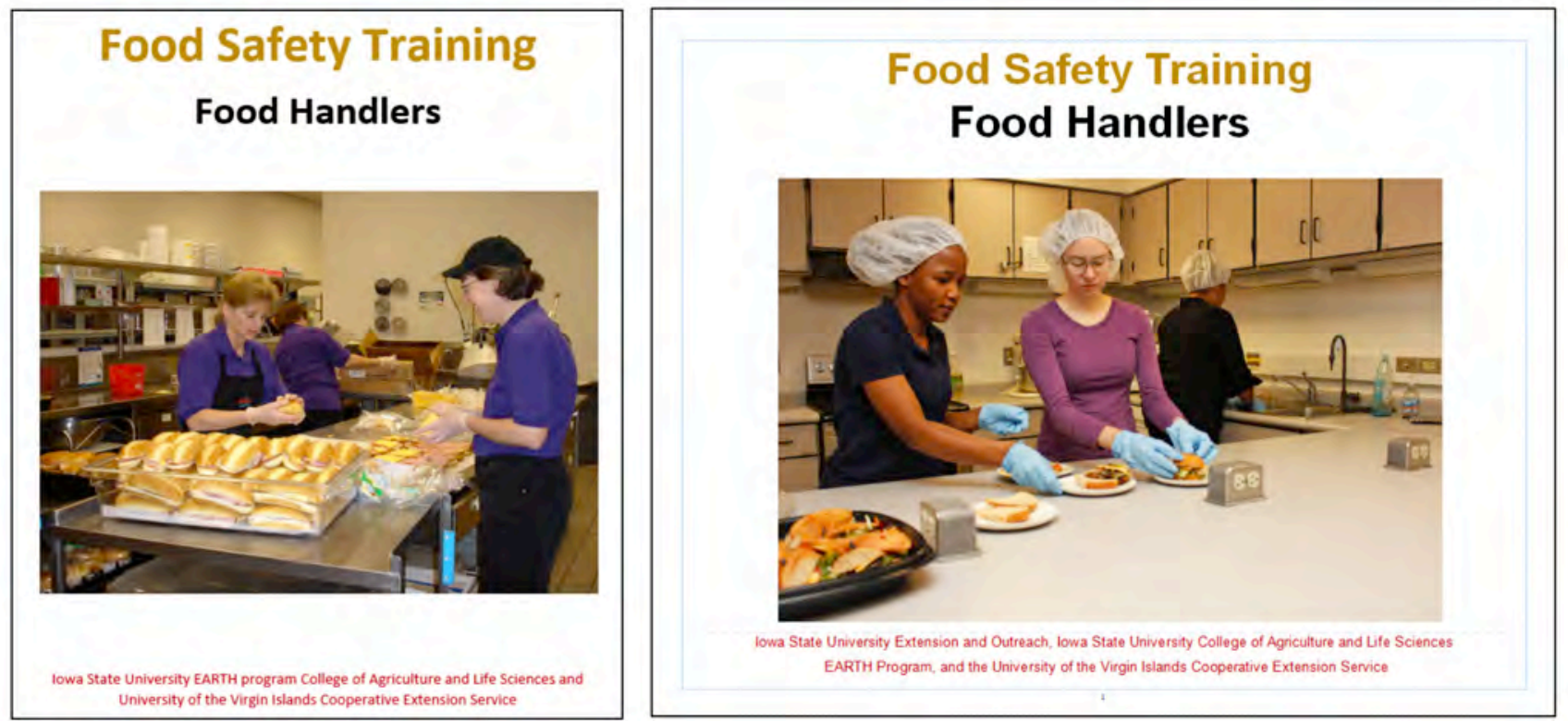

FIGURE 1. Photograph (A) of the front page of the draft of the training flip chart was replaced by the photograph (B) after evaluation of materials.

Figure 2A
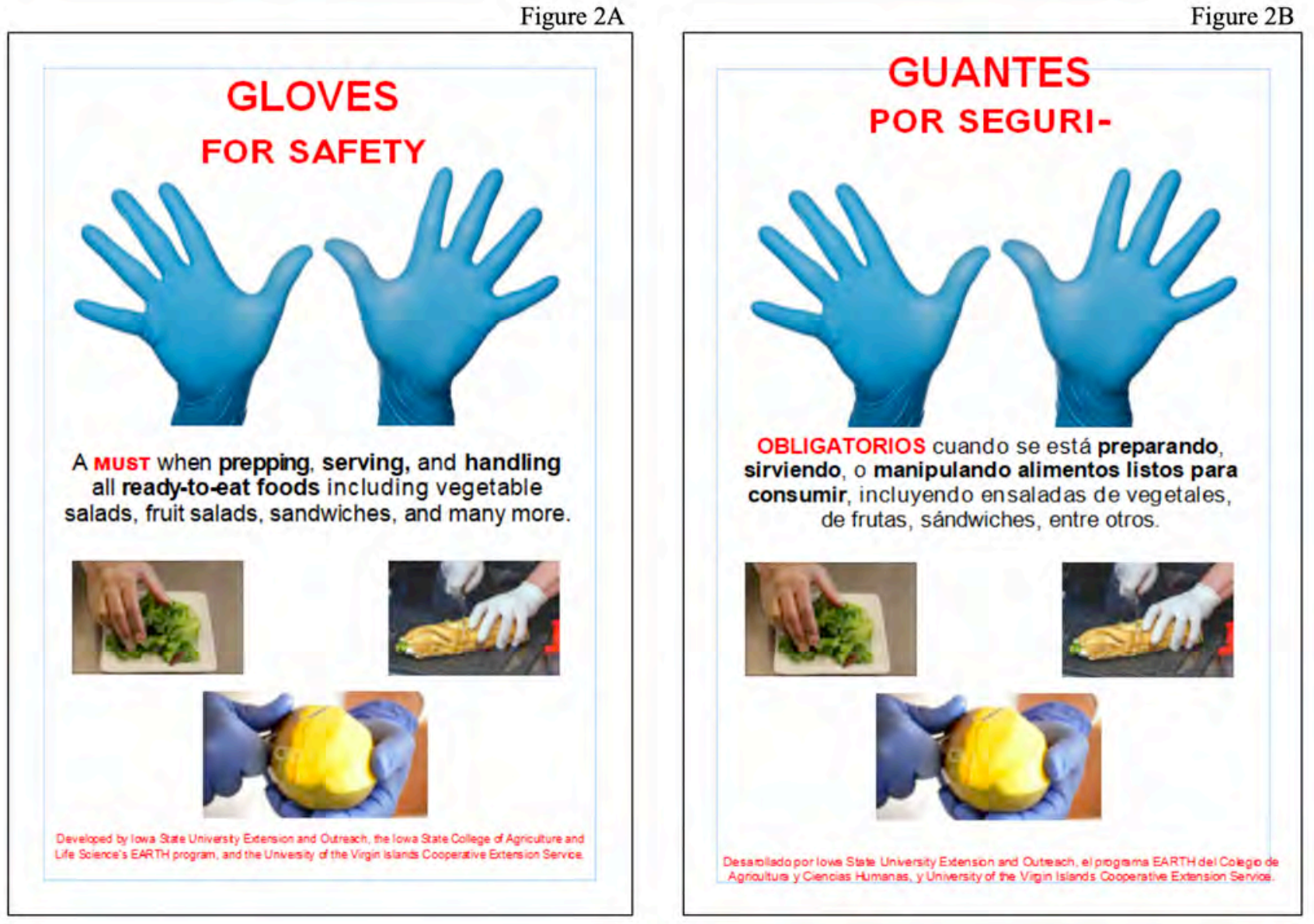

FIGURE 2. (A) Sign in English about wearing gloves and translated to Spanish (B). 
card is obtained after a negative intestinal parasites test of a submitted stool (feces) sample. Requirements include that the card is renewed annually and in the possession of the employee at all times. Based on interviews with survey participants, the following is a brief summary of the food service establishment's demographics within the study. In this study, 20 restaurants (of 23) and two charity kitchens provided various food during lunch and dinner hours (11 a.m. to 9 p.m.), including seafood, beef, pork, poultry, fresh produce, and pastries prepared in American, Italian, Asian, or Caribbean styles. The remaining 3 restaurants (of 23) provided fruits, smoothies, fruit juices, and ice cream, whereas the three roadside food vendors provided only fresh fruits and fruit juices. The roadside food vendors sold homemade unpasteurized juices, and 2 restaurants (of 23) served homemade veggie burgers and desserts. Three major food distribution companies supplied food to the retail food establishments in the USVI, and food was imported primarily from sources in California, Florida, and Massachusetts (Boston), as well as the neighboring islands. One distributor noted that on a given day, food distribution takes about 6 $\mathrm{h}$ in refrigerated trucks, and both road and ferry are used to transport food between St. Thomas and St. John islands. It was observed by the researchers that during the hot summer months, the temperature of food within the trucks was not maintained adequately because of the absence of thermometers within the trucks. The number of employees at the restaurants, charity kitchens, and roadside businesses in this study ranged from 1 to 10 , with roadside food businesses staffed by one person who was in charge of all activities, including food preparation, serving, and handling money. Managers and chefs in restaurants in this study reported taking responsibility for teaching other food handlers about appropriate food handling practices.

\section{Food safety issues within USVI retail food establishments}

The most frequent food safety issues identified (total $=172$ times) in retail food service establishments in this study were inadequate hygiene and sanitation, temperature abuse, lowquality food, and cross-contamination, which are consistent with the high-risk factors noted within the FDA Food Code (41). The leading food safety issue identified in the study was inadequate hygiene and sanitation (noted 67 of 172 times). Specific observations included that food handlers prepared food without hair coverings; handled ready-to-eat food with bare hands; did not wash hands between tasks, before glove use, or after touching money; and wore loose jewelry, painted or artificial fingernails, and visibly dirty clothing. These insanitary and unhygienic practices have been reported in health inspections as common violations of the Food Code in restaurants and roadside vended food in the United States and could be related to foodborne disease outbreaks $(1,3$, 20). In this study, 6 restaurants (of 23) had visibly dirty floors and food contact surfaces, with overflowing open trash cans that could attract flies, potentially spreading E. coli (8). The three roadside food vendors sold homemade unpasteurized fruit juices packaged in reused water bottles, a practice that has been linked to Salmonella outbreaks $(19,22)$. Key informants in this study noted that the unhygienic and unsanitary condition issues were rarely noticed during inspections.

Temperature abuse was the second food safety issue noted in this study and appeared 43 of 172 times. Respondents reported occasionally receiving meat that had thawed and refrozen, which compromises temperature control for safety (TCS) food. Of 23 restaurant managers, 9 respondents mentioned that they did not use thermometers when cooking food, because they could tell doneness by the color and texture, which can leave food undercooked (6) and has been linked to Salmonella outbreaks in shrimp and beef roasts (35, 46). Observations at two restaurants showed that raw chicken was thawed in sinks without water at room temperature overnight, which promotes multiplication of pathogens. When food supplies were delivered during busy lunch and dinner hours, employees were too occupied to store frozen and refrigerated food appropriately. The Food Code (41) provides cooking and holding temperatures, as well as thawing recommendations that minimize food safety risks of TCS food. The FDA also recommends that a thermometer be used to correctly measure temperature and doneness of TCS food to ensure microbial safety. Two respondents noted that the USVI experiences power outages during late-night hours, which has been linked to diarrheal illness from consuming temperatureabused food in New York City (25). An undependable power supply, combined with hot and humid climatic conditions, puts a strain on refrigeration and makes the USVI prone to food temperature abuse (13). The key informants in this study noted that food handlers needed to learn how to calibrate thermometers, a finding that was supported by Robertson et al. (32), who reported that up to $26 \%$ of food handlers in southwest and southern Virginia grocery store delis wanted to be trained in calibration of thermometers.

The issue of low-quality, imported food was noted 36 of 172 times, but the topic was not addressed as part of the food safety educational materials, because the food supply chain from the United States to USVI was not controlled by restaurants, charity kitchens, and roadside enterprises. Respondents that obtained food from grocery stores reported that they perceived the USVI receives food that is nearing the end of its shelf life; common food they listed were dairy products, juices, and bruised fruit and vegetable produce that spoiled shortly after it was displayed for sale on the shelves in stores. We observed that food was stored without labels of ingredients or use-by dates, which could lead to unintentional use of expired food and allergen contamination. Because the USVI imports about $97 \%$ of its food, a trend that has increased over the years $(14,48)$, it continues to rely on a few food distribution companies to provide high-quality and 
safe food from external food sources over which they have minimum control. Therefore, the USVI needs to implement strict guidelines to ensure safe food sources, whether the food is imported or locally produced. The FDA enforces labeling of food as a means to reduce food allergen contamination and performs recalls resulting from undeclared allergens (44).

The cross-contamination theme was noted 26 of 172 times. The same equipment or utensils, such as cutting boards, blenders, and knives, were used to prepare meat, allergen food, and fresh produce dishes with only a rinse between tasks. Some cutting boards were visibly chipped with rough surfaces. Cooked food, raw food, and ice were stored uncovered in the same refrigerator. These crosscontamination practices have been reported in several restaurants in the United States $(6,9,32)$ and allow transfer of pathogens and allergens between food and food contact surfaces. The Food Code (41) requires food contact surfaces to be cleaned regularly and made of material that is easy to clean. For difficult-to-clean surfaces, such as cutting boards, the FDA encourages designating specific cutting boards for meat, poultry, and seafood, designating a separate cutting board for ready-to-eat food, and replacing cutting boards when they become rough (40). These food safety issues were addressed through education intervention provided in the second phase of this study.

\section{Feedback about food safety educational materials}

Food safety educational materials received average total scores of $43.00 \pm 3.13$ and $44.10 \pm 2.20$ of 45 points (Table 2 ) in the first and second evaluations, respectively, which was not significantly different $(P=0.23)$. "Food safety educational materials received average total scores." Both scores indicate that materials could be used without further modifications (31). Average scores for specific criteria ranged from 4.45 to 4.91 and from 4.75 to 4.96 of 5 in the first and second evaluations, respectively. In both evaluations, more than $90 \%$ of respondents found materials to meet the education level, culture, and socioeconomic characteristics of the target population. They also found everyday situations were represented without offending community traditions (Table 3). In the first evaluation, $54 \%(n=6$ of 11$)$ of respondents indicated that materials needed revision, whereas in the second evaluation, $95.8 \%(n=23$ of 24$)$ of participants agreed that materials did not need revision. Respondents in the first evaluation requested that we increase the size of posters, include more people of color, and translate materials into Spanish and Creole languages. Figure 1 provides a side-by-side comparison of how the images were modified to meet this need. The recommendations by Schiffman (34) to include people that target groups can relate with, use recognizable symbols, consider cultural differences in gestures and facial expressions, and reflect cultural norms in the design of materials were followed in the development and revision of materials, which could have contributed to the high scores from evaluations.

\section{Impact of food safety educational materials on food- handling practices}

The survey conducted 6 months after dissemination of food safety educational materials evaluated the impact of materials on food handling practices and was completed by 11 restaurant managers. Figure 2 provides examples of the food safety signs about glove use in English and Spanish. Respondents stated that materials had been used to educate 89 food handlers (from 11 restaurants) about food safety, and 34 positive changes in behavior and practices were noticed (Table 4). Changes in personal hygiene behavior among food handlers had the highest frequency $(n=12$ of 34$)$, with increased hand washing frequency, wearing of clean clothing and hairnets, and trimming of fingernails. In addition, preventing cross-contamination $(n=8$ of 34$)$, controlling the temperature of TCS food ( $n=7$ of 34$)$, and cleaning

TABLE 3. Percentage of survey participants' responses to questions about cultural sensitivity of initial materials (evaluation 1) and revised materials (evaluation 2)

\begin{tabular}{|c|c|c|c|c|}
\hline \multirow[b]{2}{*}{ Questions } & \multicolumn{2}{|c|}{$\begin{array}{l}\text { Evaluation } 1 \\
\qquad(n=11)\end{array}$} & \multicolumn{2}{|c|}{$\begin{array}{l}\text { Evaluation } 2 \\
\quad(n=24)\end{array}$} \\
\hline & Yes $(\%)$ & No $(\%)$ & Yes $(\%)$ & No $(\%)$ \\
\hline $\begin{array}{l}\text { Do materials meet the educational level, cultural, geographic, and socioeconomic } \\
\text { characteristics of the target population? }\end{array}$ & 90.9 & 9.1 & 100 & 0 \\
\hline Has care been given to ensure that materials do not offend community traditions? & 90.9 & 9.1 & 100 & 0 \\
\hline Do materials represent everyday situations? & 90.9 & 9.1 & 100 & 0 \\
\hline Would you use the educational materials as they are? & 90.9 & 9.1 & 100 & 0 \\
\hline Do materials need revision or improvement before being used? & 54.5 & 45.5 & 4.2 & 95.8 \\
\hline
\end{tabular}




\section{TABLE 4. Impact of food safety educational materials on food-handling practices reported}

by retail food establishment managers ( $n=11)$, USVI

\begin{tabular}{|c|c|c|c|}
\hline & Question & Response & No./frequency \\
\hline \multirow{3}{*}{1} & \multirow{3}{*}{ Use of materials } & Posted them on wall & 7 \\
\hline & & Referred to them during training & 6 \\
\hline & & Distributed them to employees & 2 \\
\hline \multirow{3}{*}{2} & \multirow{3}{*}{ How often materials were used } & Ongoing (posted) & 3 \\
\hline & & Multiple training sessions & 5 \\
\hline & & Once & 3 \\
\hline \multirow{4}{*}{3} & \multirow{4}{*}{ Behavior changes witnessed } & $\begin{array}{l}\text { Personal hygiene (hand washing, trimming fingernails, clean clothing, } \\
\text { hairnet use, and removal of jewelry) }\end{array}$ & 12 \\
\hline & & $\begin{array}{l}\text { Temperature control (timely storage of food at delivery and during } \\
\text { preparation, using a thermometer when cooking, and installing one in } \\
\text { storage coolers) }\end{array}$ & 7 \\
\hline & & $\begin{array}{l}\text { Cross-contamination (proper glove use, separate cutting boards, } \\
\text { cleaning work surfaces, and separate food in the refrigerator) }\end{array}$ & 8 \\
\hline & & $\begin{array}{l}\text { Cleaning (cleaning the ice machine, scrubbing floors, and using a } \\
\text { sanitizer bucket) }\end{array}$ & 7 \\
\hline \multirow{2}{*}{4} & \multirow{2}{*}{ Contributing factors } & Using materials provided to us & 5 \\
\hline & & Staff oversight & 1 \\
\hline \multirow{2}{*}{5} & \multirow{2}{*}{ Challenges } & Difficult to change people's behavior & 4 \\
\hline & & Keeping them on the wall or limited space & 2 \\
\hline \multirow{4}{*}{6} & \multirow{4}{*}{ Additional resources requested } & Create a website with information and a quiz & 1 \\
\hline & & Use pictures of food with fingernails and spoiled temperature-abused food & 1 \\
\hline & & Space & 1 \\
\hline & & Hiring staff to train on these aspects & 1 \\
\hline
\end{tabular}

and sanitizing of ice machines and floors $(n=7$ of 34$)$ were reported by managers. The changes in behavior and practices noted in this study could be attributed to the possibility that educational materials presented an opportunity for managers to strengthen or start a discussion with employees about safe food-handling practices. The educational materials were readily available at the establishments and therefore provided continuous learning for food handlers and were used as reference materials during training and orientation of employees. These results are consistent with other studies that found improvement in food-handling practices after integrating both food safety knowledge and behavior in interventions $(26,28,50,51)$. Most managers in this study had taken some form of food safety training, such as ServSafe, food-handler training provided by a local health department, or training from previous chefs. Managers had at least 10 years of food service experience practicing and mastering safe food-handling practices, which gave them the confidence to teach other food handlers with the help of these materials. Hedberg et al. (17), Kassa et al. (21), and Liggans et al. (24) found that employees in restaurants with managers trained in food safety are more likely to practice safe food-handling practices and that such restaurants are less likely to appear in outbreaks. Respondents in this study reported experiencing difficulty in convincing food handlers to pay attention when handling food and having them perform safe food-handling practices consistently. Other studies support the challenge of food handlers transferring food safety knowledge into behavior $(12,50)$. This study found positive change in food-handling practices, possibly because we involved the management in the needs assessment and development of materials, which improved the materials' usefulness and the managers' commitment to reinforcing food-handling practices (10). We also used figures and photographs with minimal text in these materials and translated materials to Spanish, a native language of 
some food handlers, which made it easier for food handlers to comprehend and apply food safety knowledge $(27,34)$. The impact assessment was conducted 6 months after the dissemination of materials, which allowed more time for managers to accomplish multiple training sessions. Food handlers also had more time to internally process the food safety information and integrate new ideas with what was already known, thereby giving the opportunity for longterm knowledge retention and behavioral change. Having a postassessment after 6 months is contrary to most food safety training interventions, which are given once and provide a pretest and a posttest, usually less than 2 months apart (33, 50). A one-time training session may not be sufficient for long-term knowledge retention (29), and the short period between the intervention and the posttest may not allow sufficient time for changes to be noticed.

This study had limitations, which included a convenience sample of respondents who were not proportionally representative of the three islands of the USVI; therefore, findings may not be generalized to all retail food establishments in the USVI. The results of the impact assessment phase were gathered from the managers' self-reported observations and how they felt the interventions influenced behavior, not independently observed by researchers, which could have caused bias. A food handlers' view of the extension materials could be valuable in confirming managers' response. Nevertheless, the food safety extension materials from this study could benefit all restaurants within the USVI.

\section{CONCLUSIONS AND RECOMMENDATIONS}

Overall, this study showed that food handling practices in the USVI retail food establishments changed following use of an onsite food safety education intervention with culturally appropriate materials based on managers' self reports. Extension educators in food safety who work with culturally diverse populations should incorporate appropriate attributes when designing educational materials, because these promote continuous learning and change in practices. As the USVI Department of Health strives toward adhering to the recently adopted 2017 version of the FDA Food Code (42), it could provide food safety education resources to retail food establishments, in addition to requiring a health card for food handlers.

\section{ACKNOWLEDGMENTS}

The authors thank the Iowa State University Education and Resiliency Through Horticulture Program for partially funding the research project; Vanessa Forbes, Dale Morton, and staff of the University of the Virgin Islands Cooperative Extension Service; and Ellen Johnsen and Ana Lorena Monge of Iowa State University for their assistance in development, translation, and dissemination of extension materials.

\section{REFERENCES}

1. Allwood, P. B., T. Jenkins, C. Paulus, L. Johnson, and C. W. Hedberg. 2004. Hand washing compliance among retail food establishment workers in Minnesota. J. Food Prot. 67:2825-2828.

2. Angelo, K. M., A. L. Nisler, A. J. Hall, L. G. Brown, and L. H. Gould. 2017. Epidemiology of restaurant-associated foodborne disease outbreaks, United States, 1998-2013. Epidemiol. Infect. 145:523-534.

3. Basch, C. H., L. A. Guerra, Z. MacDonald, M. Marte, and C. E. Basch. 2015. Glove changing habits in mobile food vendors in New York City. J. Community Health 40:699-701.

4. Basch, C. H., M. Z. Wahrman, S. A. MacLean, A. Quisido, C. Ponsica, and N. Patel. 2018. Glove changing practices of mall food vendors in New Jersey. J. Community Health 43:4-10.

5. Beck, D. E., P. G. Crandall, C. A. O’Bryan, and J. C. Shabatura. 2016. Taking food safety to the next level—an augmented reality solution. J. Foodserv. Bus. Res. 19:382-395.

6. Bogard, A. K., C. C. Fuller, V. Radke, C. A. Selman, and K. E. Smith. 2013. Ground beef handling and cooking practices in restaurants in eight states. J. Food Prot. 76:2132-2140.

7. Bureau of Economic Research United States Virgin Islands. 2016. U.S. Virgin Islands Tourism Statistics. Available at: http:// usviber.org/home/. Accessed 11 May 2020.
8. Burrus, R. G., J. A. Hogsette, P. E. Kaufman, J. E. Maruniak, A. H. Simonne, and V. Mai. 2017. Prevalence of Escherichia coli O157:H7 from house flies (Diptera: Muscidae) and dairy samples in North Central Florida. J. Med. Entomol. 54:733-741.

9. Carrasco, E., A. Morales-Rueda, and R. M. García-Gimeno. 2012. Cross-contamination and recontamination by Salmonella in foods: a review. Food Res. Int. 45:545-556.

10. Clark, J., P. Crandall, and J. Reynolds. 2019. Exploring the influence of food safety climate indicators on handwashing practices of restaurant food handlers. Int. J. Hosp. Manag. 77:187-194.

11. Congressional Research Service. 2020. Economic and fiscal conditions in the U.S. Virgin Islands. Available at: https://fas. org/sgp/crs/row/R45235.pdf. Accessed 20 March 2020.

12. Cook, C. C., and R. Casey. 1979. Assessment of a foodservice management sanitation course. J. Environ. Health 41:281-284.

13. Dominianni, C., K. Lane, M. Ahmed, S. Johnson, W. McKelvey, and K. Ito. 2018. Hot weather impacts on New York City restaurant food safety violations and operations. J. Food Prot. 81:1048-1054.
14. Eileen, G. 2017. Feeding the Virgins. Available at: https://www.hakaimagazine. $\mathrm{com} /$ news/feeding-virgins/. Accessed 5 December 2019.

15. Green, L. R., and C. Selman. 2005. Factors impacting food workers' and managers' safe food preparation practices: a qualitative study. Food Prot. Trends 25:981-990.

16. Hedberg, C. W. 2013. Explaining the risk of foodborne illness associated with restaurants: the environmental health specialists network (EHS-Net). J. Food Prot. 76:2124-2124.

17. Hedberg, C. W., S. J. Smith, E. Kirkland, V. Radke, T. F. Jones, C. A. Selman, and E. H.N. W. Group. 2006. Systematic environmental evaluations to identify food safety differences between outbreak and nonoutbreak restaurants. J. Food Prot. 69:2697-2702.

18. Howells, A. D., K. R. Roberts, C. W. Shanklin, V. K. Pilling, L. A. Brannon, and B. B. Barrett. 2008. Restaurant employees' perceptions of barriers to three food safety practices. J. Am Diet. Assoc. 108:1345-1349.

19. Jain, S., S. A. Bidol, J. L. Austin, E. Berl, F. Elson, M. L. Williams, M. Deasy Iii, M. E. Moll, V. Rea, and J. D. Vojdani. 2009. Multistate outbreak of Salmonella Typhimurium and Saintpaul infections associated with unpasteurized orange juice-United States, 2005. Clin. Infect. Dis. 48:1065-1071. 
20. Jones, T. F., B. I. Pavlin, B. J. LaFleur, L. A. Ingram, and W. Schaffner. 2004. Restaurant inspection scores and foodborne disease. Emerg. Infect. Dis. 10(4):688-692.

21. Kassa, H., G. S. Silverman, and K. Baroudi. 2010. Effect of a manager training and certification program on food safety and hygiene in food service operations. Environ. Health Insights 4:EHI-S4717.

22. Krause, G., R. Terzagian, and R. Hammond. 2001. Outbreak of Salmonella serotype Anatum infection associated with unpasteurized orange juice. South. Med. J. 94:1168-1173.

23. Leshem, E., P. A. Gastañaduy, T. Trivedi, A. Laufer Halpin, J. Pringle, F. Lang N. Gregoricus, J. Vinjé, C. B. Behravesh, and U. Parashar. 2016. Norovirus in a United States Virgin Islands resort: outbreak investigation, response, and costs. J. Travel Med. 23(5):taw040. https://doi.org/10.1093/ $\mathrm{jtm} / \mathrm{taw} 040$

24. Liggans, G. L., M. S. Boyer, L. B. Williams, K. W. Destromp, and S. T. Hoang. 2019. Food safety management systems, certified food protection managers, and compliance with food safety practices associated with the control of Listeria monocytogenes in foods at restaurants. J. Food Prot. 82:1116-1123.

25. Marx, M. A., C. V. Rodriguez, J. Greenko, D. Das, R. Heffernan, A. M. Karpati, F. Mostashari, S. Balter, M. Layton, and D. Weiss. 2006. Diarrheal illness detected through syndromic surveillance after a massive power outage: New York City, August 2003. Am. J. Publ. Health 96:547-553.

26. Pellegrino, R., P. G. Crandall, and H.-S. Seo. 2016. Using olfaction and unpleasant reminders to reduce the intention-behavior gap in hand washing. Sci. Rep. 6:18890. https://doi.org/10.1038/srep18890.

27. Rajagopal, L. 2012. Use of visuals for food safety education of Spanish-speaking foodservice workers: a case study in Iowa. J. Ext. 50:1-13.

28. Rajagopal, L., S. W. Arendt, A. Shaw, C. H. Strohbehn, and K. L. Sauer. 2016. Food safety posters for safe handling of leafy greens. J. Ext. 54(2):2TOT5.

29. Raman, M., K. McLaughlin, C. Violato, A. Rostom, J. P. Allard, and S. Coderre. 2010. Teaching in small portions dispersed over time enhances long-term knowledge retention. Med. Teach. 32:250-255.

30. Ratnapradipa, D., D. Quilliam, L. Wier, and D. L. Rhodes. 2011. Food safety education: child-to-parent instruction in an immigrant population. J. Environ. Health 73:70-75.
31. Rice, M., and L. Valdivia. 1991. A simple guide for design, use, and evaluation of educational materials. Health Educ. Q 18:79-85.

32. Robertson, L. A., R. R. Boyer, B. J. Chapman, J. D. Eifert, and N. K. Franz. 2013. Educational needs assessment and practices of grocery store food handlers through survey and observational data collection. Food Control 34:707-713.

33. Rowell, A. E., M. Binkley, C. Alvarado, L. Thompson, and S. Burris. 2013. Influence of food safety training on grocery store employees' performance of food handling practices. Food Policy 41:177-183.

34. Schiffman, C. B. 1995. Visually translating educational materials for ethnic populations. Presented at the Annual Conference of the International Visual Literacy Association, Chicago, 18 to 22 October 1995. Available at: https://files.eric.ed.gov/fulltext/ED391485. pdf. Accessed July 302018

35. Shapiro, R., M.-L. Ackers, S. Lance, M. Rabbani, L. Schaefer, J. Daugherty, C. Thelen, and D. Swerdlow. 1999. Salmonella Thompson associated with improper handling of roast beef at a restaurant in Sioux Falls, South Dakota. J. Food Prot. 62:118-122.

36. Smith, L., S. A. Sirsat, and J. A. Neal. 2014. Does food safety training for non-profit food service volunteers improve food safety knowledge and behavior. Food Prot. Trends 34:156-163.

37. Sneed, J., C. Strohbehn, and S. A. Gilmore. 2004. Food safety practices and readiness to implement HACCP programs in assistedliving facilities in Iowa. J. Am. Diet. Assoc. 104:1678-1683.

38. Tull, E. S., A. Thurland, and R. E. LaPorte. 2005. Metabolic syndrome among Caribbean-born persons living in the U.S. Virgin Islands. Rev. Panam. Salud Públ. 18:418-426.

39. Turner, M. 2019. U.S. Virgin Islands reports 50 percent increase in stayovers. Available at: https://www.travelagentcentral.com/ caribbean/u-s-virgin-islands-reports-50percent-increase-stayovers. Accessed 24 January 2020.

40. U.S. Department of Agriculture. 2013. Cutting boards and food safety. Available at: https://www.fsis.usda.gov/wps/portal/fsis/ topics/food-safety-education/get-answers/ food-safety-fact-sheets/safe-food-handling/ cutting-boards-and-food-safety. Accessed 24 January 2020.

41. U.S. Food and Drug Administration. 2013. Food Code. Available at: https://www.fda. gov/food/fda-food-code/food-code-2013. Accessed 24 January 2018.
42. U.S. Food and Drug Administration. 2017 Adoption of the FDA Food Code by state and territorial agencies responsible for the oversight of restaurants and retail food stores. Available at: https://www.fda.gov/food/ fda-food-code/adoption-fda-food-codestate-and-territorial-agencies-responsibleoversight-restaurants-and-retail. Accessed 20 September 2018.

43. U.S. Food and Drug Administration. 2019. Inspections. Available at: https:// datadashboard.fda.gov/ora/cd/inspections. htm. Accessed 5 December 2019.

44. U.S. Food and Drug Administration. 2019 Recalls market withdraws and safety alerts. Available at: https://www.fda.gov/safety/ recalls-market-withdrawals-safety-alerts. Accessed 5 December 2019.

45. U.S. Virgin Islands Department of Health. n.d. How to obtain health card. Available at: https://doh.vi.gov/programs/ environmental-health/how-obtain-healthcard. Accessed 10 July 2020.

46. Venkat, H., J. Matthews, P. Lumadao, B. Caballero, J. Collins, N. Fowle, M. Kellis, M. Tewell, S. White, and R. Hassan. 2018. Salmonella enterica serotype Javiana infections linked to a seafood restaurant in Maricopa County, Arizona, 2016. J. Food Prot. 81:1283-1292.

47. VI Moving Center. 2017. Virgin Islands demographics. Available at: https://web. archive.org/web/20170217170817/http:// www.vimovingcenter.com/statistics/. Accessed 24 January 2020.

48. Walters, L. M., and K. G. Jones. 2016. Caribbean food import demand: an application of the CBS differential demand system. J. Food Distrib. Res. 47:19-37.

49. Webb, M., and A. Morancie. 2015. Food safety knowledge of foodservice workers at a university campus by education level, experience, and food safety training. Food Control 50:259-264.

50. York, V. K., L. A. Brannon, C. W. Shanklin, K. R. Roberts, B. B. Barrett, and A. D. Howells. 2009. Intervention improves restaurant employees' food safety compliance rates. Int. J. Contemp. Hosp. Manag. 21(4):459-478.

51. Yu, H., J. Neal, M. Dawson, and J. M. Madera. 2018. Implementation of behavior-based training can improve food service employees' handwashing frequencies, duration, and effectiveness. Cornell Hosp. Q. 59:70-77. 